\title{
Maternal high fat intake affects the development and transcriptional profile of fetal intestine in late gestation using pig model
}

Lianqiang Che ${ }^{1,2^{*}}$, Peilin Liu ${ }^{1,2}$, Zhengguo Yang ${ }^{1,2}$, Long Che ${ }^{1,2}$, Liang Hu ${ }^{1,2}$, Linlin Qin ${ }^{1,2}$, Ru Wang ${ }^{1,2}$, Zhengfeng Fang ${ }^{1,2}$, Yan Lin ${ }^{1,2}$, Shengyu $X u^{1,2}$, Bin Feng ${ }^{1,2}$, Jian $\mathrm{Li}^{1,2}$ and De $\mathrm{Wu}^{1,2}$

\begin{abstract}
Background: The objective of this study was to investigate the effects of maternal high fat intake on intestinal development and transcriptional profile.

Methods: Eight gilts with similar age and body weight were randomly allocated into 2 groups receiving the control and high fat diets (HF diet) from d 30 to 90 of gestation, with 4 gilts each group and one gilt each pen. At d 90 of gestation, two fetuses each gilt were removed by cesarean section. Intestinal samples were collected for analysis of morphology, enzyme activities and transcriptional profile.

Results: The results showed that feeding HF diet markedly increased the fetal weight and lactase activity, also tended to increase intestinal morphology. Porcine Oligo Microarray analysis indicated that feeding HF diet inhibited $64 \%$ of genes (39 genes down-regulated while 22 genes up-regulated),which were related to immune response, cancer and metabolism, also markedly modified 33 signal pathways such as antigen processing and presentation, intestinal immune network for IgA production, Jak-STAT and TGF-ß signaling transductions, pathways in colorectal cancer and glycerolipid metabolism.
\end{abstract}

Conclusion: Collectively, it could be concluded that maternal high fat intake was able to increase fetal weight and lactase activity, however, it altered the intestinal immune response, signal transduction and metabolism.

Keywords: Maternal nutrition, Offspring, Immune, Cancer, DNA microarray

\section{Background}

Gastrointestinal tract (GIT), as an internal organ to digest nutrients and resist exogenous antigens, starts to develop at early gestation and mature rapidly in late gestation for extra-uterine life [1]. The functional maturation of GIT occurs in both pre- and postnatal period, which is largely influenced by maternal nutrition [2]. Maternal diet has been shown to affect the fetal development and organ function in mammalian animals [3]. Our recent study also suggests that maternal nutrition

\footnotetext{
* Correspondence: clianqiang@hotmail.com

'Institute of Animal Nutrition, Sichuan Agricultural University, No.46, Xinkang

Road, Ya'an, Sichuan 625014, People's Republic of China

${ }^{2}$ Key Laboratory for Animal Disease-Resistance Nutrition, Ministry of

Education, No.46, Xinkang Road, Ya'an, Sichuan 625014, People's Republic of China
}

(c) 2016 Che et al. Open Access This article is distributed under the terms of the Creative Commons Attribution 4.0 International License (http://creativecommons.org/licenses/by/4.0/), which permits unrestricted use, distribution, and reproduction in any medium, provided you give appropriate credit to the original author(s) and the source, provide a link to the Creative Commons license, and indicate if changes were made. The Creative Commons Public Domain Dedication waiver (http://creativecommons.org/publicdomain/zero/1.0/) applies to the data made available in this article, unless otherwise stated. in which maternal over-nutrition would improve intestinal morphology, enzyme activities and gene expressions of nutrient transporters in newborn pigs [4]. However, it has been reported that maternal high-fat intake or -related obesity could impair gut barrier, enhance gene expression of pro-inflammatory cytokines in offspring intestine, thus predisposes offspring to inflammatory bowel disease $[5,6]$. However, the underlying mechanism for the effects of maternal high fat intake on the intestinal development and function are limited. The current study was designed to investigate the effects of maternal high fat intake on fetal intestinal development and function by measuring parameters on morphology, enzyme activities and transcriptional profiles. Oligo Microarray was used to analyze the genomic 
response of fetal intestine to maternal high fat intake. Pigs were chosen as the experimental animal, because it is generally accepted to be closer to humans than other laboratory or domestic animals in terms of gastrointestinal anatomy, physiology, nutrition and microbiota [2, 7-9].

\section{Methods}

The experimental procedure was approved by the University of Sichuan Agricultural Animal Care Advisory committee, and followed the current law of animal protection.

\section{Animals and diets}

A total of 8 Meishan (MS) gilts (aged at $266 \pm 15 \mathrm{~d}$, initial body weight at $73 \pm 4 \mathrm{~kg}$ ) were used in this study. After inseminated with MS semen, eight gilts were randomly allocated to receive control diet (CON diet with $14 \%$ Protein, $34.7 \%$ Starch and $2.8 \%$ Fat) and high fat diet (HF diet with 14\% Protein, $34.7 \%$ Starch and $7.3 \%$ Fat), respectively. The $4.5 \%$ of soy oil was added into $\mathrm{CON}$ diet to formulate HF diet, as a result, HF diet contained digestive energy $(\mathrm{DE})$ at $3.0 \mathrm{Mcal} / \mathrm{kg}$, while $\mathrm{CON}$ diet contained DE at $2.6 \mathrm{Mcal} / \mathrm{kg}$. According to the fatty acids contents of feed ingredients by NRC (2012), the contents of saturated, mono- and polyunsaturated fatty acids were $0.25 \%, 0.48 \%, 0.83 \%$ in $\mathrm{CON}$ diet and $0.84 \%, 1.78 \%, 3.44 \%$ in HF diet, respectively. The other nutrient levels were similar between 2 diets, meeting or exceeding nutrient requirements recommended by NRC (2012). All gilts were housed individually in stall $(2.5 \mathrm{~m}$ length $\times 1.6 \mathrm{~m}$ width), receiving the same amount of diets at $2.0 \mathrm{~kg}$ from d 1 to 30 of gestation and $2.5 \mathrm{~kg}$ from d 30 to 90 of gestation, with free access to water. Environmental temperature was maintained at approximately $24{ }^{\circ} \mathrm{C}$ during the experiment.

\section{Sample collection}

At d 90 of gestation, gilts were weighed (in average $128 \mathrm{~kg}$ at $\mathrm{HF}$ vs. $117 \mathrm{~kg}$ at CON group) and anaesthetized by intramuscularly injecting Zoletil 50 at the dose of $0.1 \mathrm{mg} /$ $\mathrm{kg}$ (Virbac, France), then the uterus were removed from gilts. Two fetuses near the average fetal weight were collected each gilt. As the previous study, duodenal, jejunal and ileal samples (approximately $2 \mathrm{~cm}$ ) were preserved in $4 \%$ paraformaldehyde solution, then embedded in paraffin. Each tissue sample of duodenum, jejunum and ileum was used to prepare 5 slides, each slide had three sections (5 mm thickness), which were stained with eosin and haematoxylin, 20 well-oriented villi and crypts each section were measured for morphology (Optimus software version 6.5, Media Cybergenetics, North Reading, MA, USA), and villous height to crypt depth ratio (VCR) was calculated [10]. A section of duodenum, jejunum and ileum tissues were collected and snap-frozen in liquid nitrogen, then stored at $-80{ }^{\circ} \mathrm{C}$ for analysis of enzyme activities, RNA microarray and gene expression.

\section{Enzyme activities}

According to the previous study, the thawing samples of jejunum and ileum were weighed (approximately $2 \mathrm{~g}$ ), then 9 times volume of $50 \mathrm{mM}$ Tris- $\mathrm{HCl}$ buffer $(\mathrm{pH} 7 \cdot 0)$ than the sample weight were added and homogenized for $40 \mathrm{~s}$ by homogenate machine (Homogenizer Power Gen $125^{\mathrm{nt}}$, ThermoFisher Scientific, MA, USA) and centrifuged at $3000 \mathrm{~g}$ for $10 \mathrm{~min}$, the supernatant was collected and stored at $-20{ }^{\circ} \mathrm{C}$ [11]. Total protein was extracted from the supernatant and protein concentration was determined by bicinchoninic acid protein assay with bovine serum albumin as the standard (Solarbio, Inc., Beijing, China). Activities of disaccharidase including maltase, sucrase and lactase were measured using commercial kits (Nanjing Jiancheng Bioengineering, Nanjing, China). The absorbance at $450 \mathrm{~nm}$ was determined with spectrophotometer (Beckman Coulter DU-800; Beckman Coulter, Inc., CA, USA). Activities of disaccharidase were presented as $\mathrm{U} / \mathrm{mg}$ protein. One unit (U) was defined by $1 \mathrm{nmol}$ of maltose, sucrose and lactose as a substrate for the enzymatic reaction, respectively.

\section{RNA extraction}

The frozen ileum tissues were used for RNA extraction, 4 sections around luminal circle each tissue were collected and pooled for RNA extraction. Total RNA was extracted using Trizol reagent (Invitrogen, Carlsbad, CA, USA) and quantified using spectrophotometry based on absorbance at $260 \mathrm{~nm}$, the RNA quality was monitored using Agilent 2100 Bioanalyzer (Agilent Technologies, Palo Alto, CA, USA). The equal amount of RNA from 2 fetus each gilt were pooled together.

\section{Porcine oligo microarray}

As in our previous study, Agilent Porcine Oligo Microarray $(4 \times 44 \mathrm{~K})$ containing more than 40,000 probes were used [12]. Cyanine-3 (Cy3)-labeled cRNA was prepared from $0.5 \mu \mathrm{g}$ RNA using the One-Color Low RNA Input Linear Amplification PLUS kit (Agilent Technologies,Palo Alto, CA, USA) according to the manufacturer's instructions, and followed by the RNeasy column purification (Qiagen, Valencia, CA, USA). Dye incorporation and cRNA yield were checked with the NanoDrop ND-1000 Spectrophotometer. Microarrays were hybridized at $65^{\circ} \mathrm{C}$ for $17 \mathrm{~h}$ and washed with a Gene Expression Washing Buffer Kit (Agilent Technologies, Palo Alto, CA, USA). Slides were scanned with an Agilent microarray scanner.

\section{Microarray data collection and analysis}

Microarray data were collected and analyzed using Agilent G2567AA Feature Extraction software, following 
Table 1 Primer sequences of genes selected for analysis by real-time RT-PCR

\begin{tabular}{|c|c|c|c|c|}
\hline Genes & GenBank accession & Primer sequence $\left(5^{\prime} \sim 3^{\prime}\right)$ & Product length (bp) & $\operatorname{Tm}\left({ }^{\circ} \mathrm{C}\right)$ \\
\hline \multirow[t]{2}{*}{ HSPA1L } & NM_001123128.1 & F:CGCTTTGACCTGACTGGAAT & 120 & 60 \\
\hline & & R:CTTGCCTGTGCTCTTGTCC & & \\
\hline \multirow[t]{2}{*}{ CD8A } & NM_001001907.1 & F:GCTGGACACCCGTTACATCT & 100 & 60 \\
\hline & & R:CGAGCAGAAATAGTAGCCTTGG & & \\
\hline \multirow[t]{2}{*}{ CD40 } & NM_214194.1 & F:GGTTCGTCTGCCTCTGAAGT & 104 & 60 \\
\hline & & R:GGCTGTTTGTTGGGTATTGG & & \\
\hline \multirow[t]{2}{*}{ PSTPIP1 } & NM_001244186.1 & F:CTCCTTTGACTCCCTGAAGC & 114 & 60 \\
\hline & & R:TTCTGCCTCTCTCGGAACTC & & \\
\hline \multirow[t]{2}{*}{ SLA-DQA1 } & NM_001114062.2 & F:TGGACCTGGAGAAGAAGGAG & 132 & 60 \\
\hline & & R:TGGAGCGTTTAGTCACGATG & & \\
\hline \multirow[t]{2}{*}{ STAT2 } & NM_213889.1 & F:TCCCAAATCACAAGGTTTCC & 109 & 60 \\
\hline & & R:CAGATAGCCGAAGTCCCAAA & & \\
\hline \multirow[t]{2}{*}{ GK } & NM_001143708.1 & F:GCAGGTAGATGGAGGGATGA & 107 & 60 \\
\hline & & R:CCAGGGCAGTTGTTTCAGG & & \\
\hline \multirow[t]{2}{*}{ BMP7 } & NM_001105290.1 & F:TCCAGGGCAAGCACAACT & 172 & 60 \\
\hline & & R:TCGGTGAGGAAGTGGCTATC & & \\
\hline \multirow[t]{2}{*}{ PIK3R5 } & NM_213851.1 & F:CTGTCATTCCCTCCTTCCAA & 117 & 60 \\
\hline & & R:GCCACCCTCCTCTTACTCTG & & \\
\hline \multirow[t]{2}{*}{ SLA-DRB1 } & NM_001113695.1 & F:TCTGCTCTITGTTGCTGTGG & 120 & 60 \\
\hline & & R:GGATGCTTGCTTGGAGTGTC & & \\
\hline \multirow[t]{2}{*}{ THY1 } & XM_005667396.1 & F:GGCATCGCTCTCTTGCTAAC & 125 & 60 \\
\hline & & R:GGCAGGTTGGTGGTATTCTC & & \\
\hline \multirow[t]{2}{*}{ TGFB1 } & NM_214015.1 & F:AAGCGGCAACCAAATCTATG & 113 & 60 \\
\hline & & R:CCCGAGAGAGCAATACAGGT & & \\
\hline \multirow[t]{2}{*}{ SLA-1 } & NM_001097431.1 & F:GTCAAGGAAACCGCACAGAT & 113 & 60 \\
\hline & & R:CCCAAGTAGCAGCCAAACAT & & \\
\hline \multirow[t]{2}{*}{ CD74 } & NM_213774.1 & F:ATGGACGGTGTGAACTGGA & 100 & 60 \\
\hline & & R:GAACCTCAAAGGGTGTCTCCT & & \\
\hline \multirow[t]{2}{*}{ SOD2 } & XM_005659113.1 & F:CCTTCACTTTGCCTCTTGGT & 127 & 60 \\
\hline & & R:CACCGTTAGGGCTCAGATTT & & \\
\hline \multirow[t]{2}{*}{ ACTA2 } & XM_005671254.1 & F:GTCCACCTTCCAGCAAATGT & 105 & 60 \\
\hline & & R:AGACAGCGAGCAGGGTAAGT & & \\
\hline \multirow[t]{2}{*}{ SULT1E1 } & NM_213992.1 & F:TGAAGTCTCATCTGCCACCT & 101 & 60 \\
\hline & & R:AGAAACGACCACATCCTTGG & & \\
\hline \multirow[t]{2}{*}{$\beta$-actin } & DQ845171.1 & F:GGCGCCCAGCACGAT & 66 & 60 \\
\hline & & R:CCGATCCACACGGAGTACTTG & & \\
\hline
\end{tabular}

HSPA1L heat shock $70 \mathrm{kDa}$ protein 1-like, CD8A CD8a molecule (CD8A), CD40 CD40 molecule, TNF receptor superfamily member 5; SLA-DQA1 MHC class II histocompatibility antigen SLA-DQA, PSTPIP1 proline-serine-threonine phosphatase interacting protein 1, STAT2 signal transducer and activator of transcription 2, GK glycerol kinase, BMP7 bone morphogenetic protein 7, PIK3R5 phosphoinositide-3-kinase, regulatory subunit 5, SLA-DRB1 MHC class II histocompatibility antigen SLA-DRB1, THY1 Thy-1 cell surface antigen, TGFB1 transforming growth factor, beta 1, SLA-1 MHC class I antigen 1, CD74 CD74 molecule, major histocompatibility complex, class II invariant chain, SOD2 superoxide dismutase 2, mitochondrial, ACTA2 actin, alpha 2, smooth muscle, aorta, SULT1E1 sulfotransferase family $1 \mathrm{E}$, estrogen-preferring, member 1

Agilent's direct labeling protocol. The quantile method was used to normalize the probe intensities across the whole set of arrays. Three criteria were used to determine statistically significant differential expression of intestinal genes between fetus from CON and HF gilts: 1) statistical significance: $P$ value as determined by $t$-test $<0.05 ; 2$ ) 
reliability: a spot quality flag P ("P," a quality flag assigned by the software package); 3) relevance: a minimal fold change between the means of the 2 groups $>1.5$.

\section{Real-time PCR}

In order to verify the microarray data, RNA samples used for porcine oligo microarray were applied to the quantitative real-time PCR (qPCR), which was performed in duplicate to amplify the target and reference genes, using one step SYBR Prime-Script ${ }^{\text {tm }}$ RT-PCR kit II (Catalog no. DRR086A, Takara, Japan) by Real-Time PCR (ABI 7900HT, Applied Biosystems, CA, USA). The sequences of primers and length of products were shown at Table 1 . The reaction mixture $(10.0 \mu \mathrm{L})$ contained $5.6 \mu \mathrm{L}$ of freshly pre-mixed one step SYBR Green Real-Time PCR Master mix and Prime Script ${ }^{\mathrm{tm}}$ Enzyme Mix, $0.8 \mu \mathrm{mol} / \mathrm{L}$ of the primers, and 100 ng of RNA template. The qPCR program was designed with one cycle of $42{ }^{\circ} \mathrm{C}$ for $5 \mathrm{~min}$, one cycle of $95{ }^{\circ} \mathrm{C}$ for $10 \mathrm{~s}, 40$ cycles of $95^{\circ} \mathrm{C}$ for $5 \mathrm{~s}$ and $60{ }^{\circ} \mathrm{C}$ for $34 \mathrm{~s}$, followed by the dissociation step at $95^{\circ} \mathrm{C}$ for $15 \mathrm{~s}$, $60{ }^{\circ} \mathrm{C}$ for $60 \mathrm{~s}$ and $95^{\circ} \mathrm{C}$ for $15 \mathrm{~s}$. At the end of amplification, melting curve analysis was performed to identify amplification specificity. Amplification of $B$-actin was used to normalize gene expression through the double standard curves method [11].

\section{Statistical analysis}

The detected data by samples from two fetuses each gilt were averaged and taken as one independent data involving into statistical analysis model. In addition to Oligo Microarray and GPCR data, all other data on growth performance, intestinal morphology and enzyme activities were analyzed via the $\mathrm{t}$ Student's $t$ test for a completely randomized design using SAS (SAS, Cary, $\mathrm{NC})$. Results were expressed as the mean \pm SD. Differences were considered to be significant when $P<0.05$, while a tendency was considered when $0.05<P<0.10$.

\section{Results}

\section{Growth performance}

Feeding HF diet markedly increased the fetal weight (in average $585 \mathrm{~g}$ vs.508 g, $P<0.05)$ at $\mathrm{d} 90$ of gestation.

\section{Morphology and enzyme activities}

Feeding HF diet tended to increase intestinal villous height $(P=0.055)$, but decrease crypt depth $(P=0.098)$ of fetus (Fig. 1). Meanwhile, the lactase activity was markedly increased $(+55 \%, P<0.05)$ by feeding HF diet relative to $\mathrm{CON}$ diet, whereas the maltase activity did not markedly differ between groups (Fig. 2), and sucrase activity could not be detected in fetal intestine. Gene expression of digestive enzymes were not markedly differ between two groups (Additional file 1).

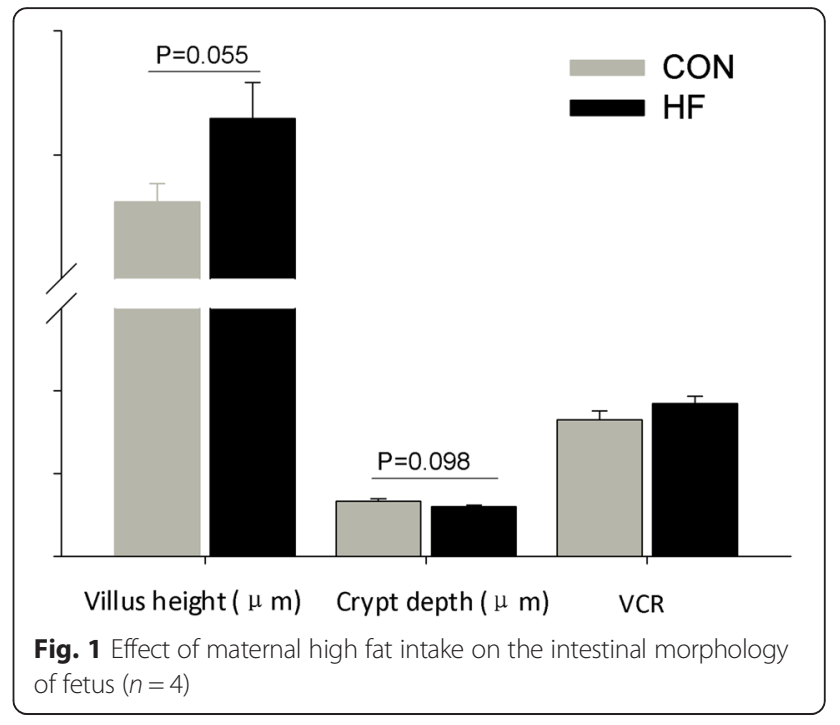

Differentially expressed genes in fetal intestine A total of 61 genes were differentially expressed (at least 1.5 fold change, $P<0.05$ ), and 39 genes were downregulated while 22 genes were up-regulated (Table 2, Fig. 3). The changes in mRNA expression detected by porcine oligo microarrays were further validated by

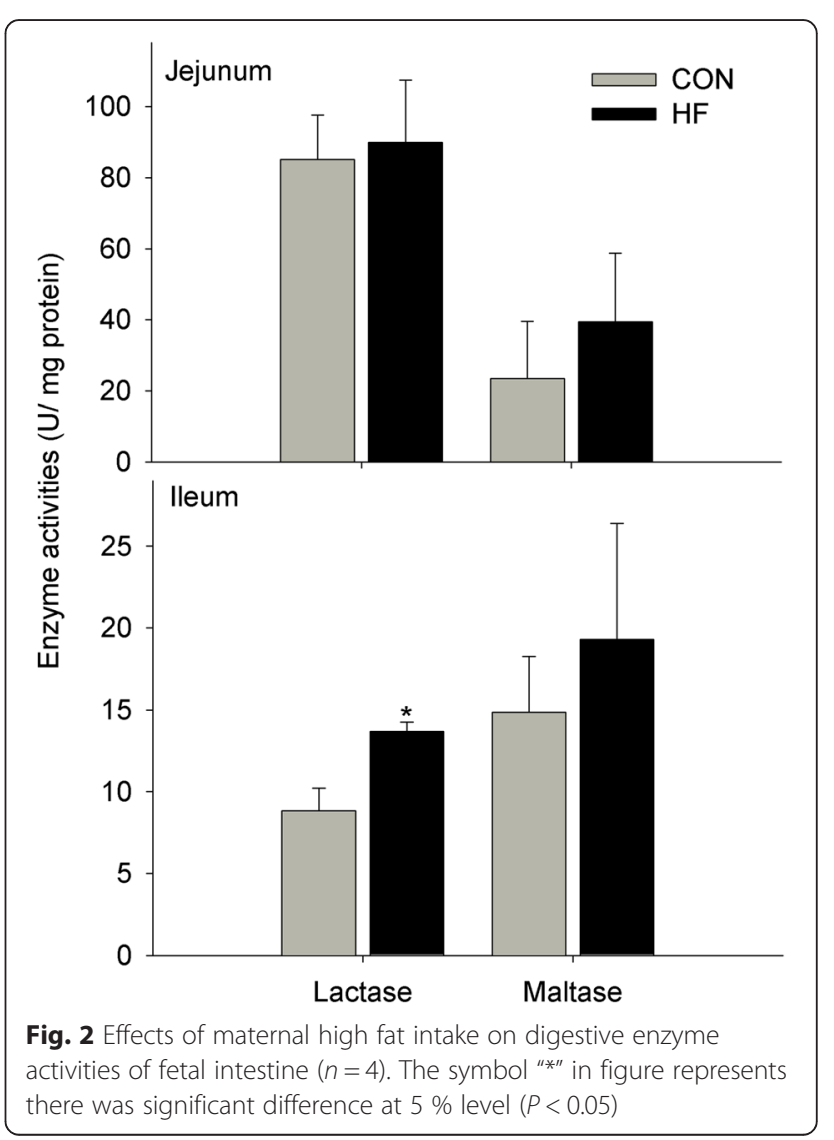


Table 2 Maternal high fat intake markedly regulated intestinal gene expressions related to immune response, signal transduction, cancer and metabolism

\begin{tabular}{|c|c|c|c|}
\hline Gene Symbol ${ }^{a}$ & Gene name & Fold change $^{b}$ & $P$ value \\
\hline CCR7 & chemokine (C-C motif) receptor 7 & -2.94 & 0.023 \\
\hline HSPA1L & heat shock $70 \mathrm{kDa}$ protein 1-like & -2.50 & 0.016 \\
\hline CD8A & CD8a molecule (CD8A) & -2.44 & 0.035 \\
\hline CD3E & CD3e molecule, epsilon (CD3-TCR complex) (CD3E) & -2.27 & 0.033 \\
\hline STK17B & serine/threonine kinase $17 \mathrm{~b}$ & -2.00 & 0.026 \\
\hline CD40 & CD40 molecule, TNF receptor superfamily member 5 & -2.00 & 0.011 \\
\hline CD2 & CD2 molecule & -1.89 & 0.026 \\
\hline SLA-DQA1 & MHC class II histocompatibility antigen SLA-DQA & -1.85 & 0.002 \\
\hline PSTPIP1 & proline-serine-threonine phosphatase interacting protein 1 & -1.85 & 0.007 \\
\hline SLAMF6 & SLAM family member 6 & -1.82 & 0.046 \\
\hline TP53INP1 & tumor protein p53 inducible nuclear protein 1 & -1.82 & 0.000 \\
\hline FAM78A & family with sequence similarity 78 , member $A$ & -1.79 & 0.015 \\
\hline BCL2A1 & $\mathrm{BCL}$ 2-related protein $\mathrm{A} 1$ & -1.79 & 0.023 \\
\hline ARHGAP25 & Rho GTPase activating protein 25 & -1.75 & 0.011 \\
\hline CD1.1 & CD1 antigen & -1.72 & 0.007 \\
\hline STAT2 & signal transducer and activator of transcription 2 & -1.69 & 0.042 \\
\hline ARHGAP30 & Rho GTPase activating protein 30 & -1.69 & 0.036 \\
\hline BCL2A1 & $\mathrm{BCL} 2$-related protein $\mathrm{A} 1$ & -1.69 & 0.040 \\
\hline IL10RB & interleukin 10 receptor, beta & -1.67 & 0.013 \\
\hline GK & glycerol kinase & -1.64 & 0.041 \\
\hline LTB & mRNA, clone:MLN010057G03, expressed in mesenteric lymph nodes & -1.64 & 0.031 \\
\hline LCP1 & lymphocyte cytosolic protein 1 (L-plastin) & -1.61 & 0.014 \\
\hline PGM1 & phosphoglucomutase 1 & -1.61 & 0.045 \\
\hline NRROS & negative regulator of reactive oxygen species & -1.59 & 0.049 \\
\hline CYTH4 & cytohesin 4 & -1.59 & 0.039 \\
\hline BMP7 & bone morphogenetic protein 7 & -1.59 & 0.024 \\
\hline PIK3R5 & phosphoinositide-3-kinase, regulatory subunit 5 & -1.56 & 0.009 \\
\hline RGS14 & regulator of G-protein signaling 14 & -1.54 & 0.049 \\
\hline GLRX & glutaredoxin (thioltransferase) & -1.54 & 0.025 \\
\hline SLA-DRB1 & MHC class II histocompatibility antigen SLA-DRB1 & -1.52 & 0.028 \\
\hline LPAR2 & lysophosphatidic acid receptor 2 & -1.52 & 0.016 \\
\hline THY1 & Thy- 1 cell surface antigen & -1.52 & 0.028 \\
\hline TGFB1 & transforming growth factor, beta 1 & -1.52 & 0.022 \\
\hline BAZ1A & bromodomain adjacent to zinc finger domain, 1A & -1.52 & 0.024 \\
\hline CCDC69 & coiled-coil domain containing 69 & -1.49 & 0.048 \\
\hline LRRK2 & leucine-rich repeat kinase 2 & -1.49 & 0.022 \\
\hline SLA-1 & MHC class I antigen 1 & -1.49 & 0.018 \\
\hline CD74 & CD74 molecule, major histocompatibility complex, class II invariant chain & -1.49 & 0.038 \\
\hline SOD2 & superoxide dismutase 2 , mitochondrial & 1.51 & 0.004 \\
\hline ILF2 & interleukin enhancer binding factor 2 & 1.51 & 0.021 \\
\hline CYP39A1 & cytochrome P450, family 39, subfamily A, polypeptide 1 & 1.52 & 0.043 \\
\hline $\mathrm{JPH} 4$ & junctophilin 4 & 1.52 & 0.026 \\
\hline ATCAY & ataxia, cerebellar, Cayman type & 1.53 & 0.008 \\
\hline
\end{tabular}


Table 2 Maternal high fat intake markedly regulated intestinal gene expressions related to immune response, signal transduction, cancer and metabolism (Continued)

\begin{tabular}{|c|c|c|c|}
\hline MATN2 & mRNA, clone:OVR010041A03, expressed in ovary & 1.53 & 0.016 \\
\hline CRMP1 & Uncharacterized protein & 1.54 & 0.039 \\
\hline RTDR1 & mRNA, clone:UTR010010H08, expressed in uterus. & 1.55 & 0.001 \\
\hline SPARCL1 & SPARC-like 1 (hevin) & 1.56 & 0.035 \\
\hline MATN2 & mRNA, clone:OVR010041A03, expressed in ovary & 1.56 & 0.019 \\
\hline CCN2 & connective tissue growth factor & 1.57 & 0.042 \\
\hline TUSC3 & mRNA, clone: HTMT10103A12, expressed in hypothalamus & 1.58 & 0.009 \\
\hline ID4 & inhibitor of DNA binding 4, dominant negative helix-loop-helix protein & 1.58 & 0.024 \\
\hline SPARC & secreted protein, acidic, cysteine-rich (osteonectin) & 1.60 & 0.035 \\
\hline MEP1A & meprin A, alpha (PABA peptide hydrolase) & 1.63 & 0.018 \\
\hline ARL10 & ADP-ribosylation factor-like 10 & 1.64 & 0.036 \\
\hline STMN2 & stathmin-like 2 & 1.64 & 0.039 \\
\hline ACTA2 & actin, alpha 2, smooth muscle, aorta & 1.66 & 0.016 \\
\hline SHISA2 & shisa family member 2 & 1.76 & 0.029 \\
\hline UCHL1 & ubiquitin carboxyl-terminal esterase L1 (ubiquitin thiolesterase) & 1.79 & 0.014 \\
\hline OCRL & oculocerebrorenal syndrome of Lowe & 2.01 & 0.008 \\
\hline SULT1E1 & sulfotransferase family $1 E$, estrogen-preferring, member 1 & 2.59 & 0.013 \\
\hline
\end{tabular}

${ }^{a}$ Genes were selected from the Kyoto Encyclopedia of Genes and Genomes pathways related to intestinal immune response, signal transduction, cancer and metabolism (http://www.genome.jp/kegg/pathway.html)

${ }^{\mathrm{b}}$ The fold change was based on the ratio of HF group to CON group, $n=4$ subpools/group

qRT-PCR (Table 3). Given their participation in crucial biological process and modulating signal pathways on immune response, cancer and metabolism, these genes were chosen for Real-Time PCR analysis.

\section{Analysis of gene ontology and signal pathway}

The differentially expressed genes were clustered according to their biological process ontology by Gene Ontology (GO) analysis from the SBS analysis system (http://www.shanghaibiotech.com/). A large number of these genes were associated with antigen processing and presentation [i.e. D74, CD8A, SLA-DOB, SLA-DRB1, SLA-DQA, HSPA1L], intestinal immune network for IgA production [i.e. CD40, IL6, TGF $\beta 1$ ], Jak-STAT signaling pathway [i.e. IL6, STAT2 and PIK3R5], TGF- $ß$ signaling pathway [i.e. TGF- $\beta$ and PIK3R5], pathways in cancer [i.e. LEF1, PIK3R5, NOS2] and glycerolipid metabolism [i.e. GK, PNLIPRP1] et al. (Table 2, Fig. 4).

Consequently, maternal HF intake markedly modified 33 signal pathways $(P<0.01)$ (Table 4$)$, which were mainly involved in immune response (i.e. antigen processing and presentation, intestinal immune network for IgA production, primary immunodeficiency), signaling transduction (i.e. TGF- $\beta$ signaling pathway, chemokine signaling pathway), cancer (i.e. colorectal cancer, pathways in cancer), metabolism (i.e. glycerolipid metabolism, nitrogen metabolism), signaling molecules and interaction (i.e. cytokine-cytokine receptor interaction, cell adhesion molecules, neuroactive ligand-receptor interaction).

\section{Discussion}

Some studies have indicated that maternal nutrition would affect the intestinal development and function of offspring [4, 13-15].

In this study, maternal high fat intake increased intestinal villous height and lactase activity, which is similar as our recent study that maternal over-nutrition markedly increased birth weight, accordingly intestinal morphology as well as lactase activity [4]. It may be rational that the heavier birth weight needs higher lactase activity in preparation for better degradation of lactose, which is a crucial energy source in neonatal period [16]. However, a recent study indicated that maternal high fat intake would induce intestinal inflammation and poor gut barrier function in the offspring of mice [5]. In this study, porcine oligo miacro array analysis was used to determine the genomic response of intestine to maternal high fat intake, in an attempt to reveal the potential mechanism. According to the strict selection criteria, we found a total of 61 genes were differentially regulated and $64 \%$ of them (39 genes) was down-regulated by HF diet. With the bioinformatics analysis, these down- 


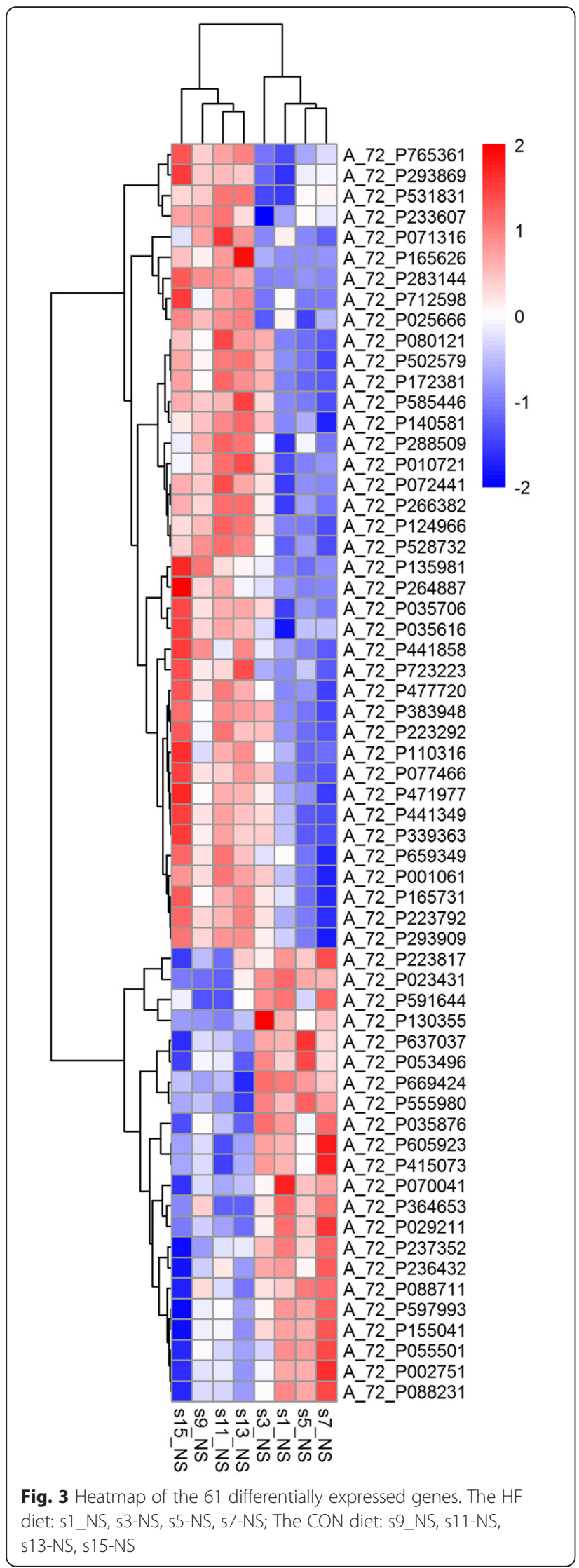

Table 3 Differentially expressed genes in fetal intestine by maternal high fat intake and validated by $\mathrm{QPCR}$

\begin{tabular}{llll}
\hline & & \multicolumn{2}{l}{ Fold change $^{\mathrm{b}}$} \\
Gene symbol $^{\mathrm{a}}$ & CDNA Microarray & qPCR & $P$ value \\
\hline ACTA2 & 1.66 & 1.10 & 0.246 \\
SULT1E1 & 2.59 & 1.88 & 0.002 \\
SOD2 & 1.51 & 1.75 & 0.036 \\
BMP7 & -1.59 & -1.09 & 0.722 \\
CD40 & -2.00 & -1.74 & 0.116 \\
CD74 & -1.49 & -1.36 & 0.029 \\
CD8A & -2.44 & -1.85 & 0.049 \\
GK & -1.64 & -1.33 & 0.041 \\
HSPAIL & -2.50 & -1.60 & 0.027 \\
PIK3R5 & -1.56 & -1.07 & 0.644 \\
PSTPIP1 & -1.85 & -1.48 & 0.083 \\
SLA-1 & -1.49 & -1.45 & 0.097 \\
SLA-DQA1 & -1.85 & -1.79 & 0.003 \\
SLA-DRB1 & -1.52 & -1.33 & 0.136 \\
STAT2 & -1.69 & -1.18 & 0.125 \\
TGF- $\beta$ & -1.52 & -1.19 & 0.296 \\
THY1 & -1.52 & -1.29 & 0.118 \\
\hline
\end{tabular}

${ }^{\mathrm{a}} \mathrm{Genes}$ were selected on the basis of their crucial role on regulating intestinal immune response (i.e.SLA-DRB1,SLA-DQA,HSPA1L,CD74,CD40), colorectal cancer (i.e.TGF- $\beta$,PIK3R5), signal transduction (i.e. PSTPIP1,BMP7,STAT2) and metabolism (i.e.GK, SULT1E1). These genes by DNA microarray were all significantly regulated $(P<0.05$, at least 1.5 fold change)

${ }^{\text {b} T h e ~ f o l d ~ c h a n g e ~ w a s ~ b a s e d ~ o n ~ t h e ~ r a t i o ~ o f ~ H F ~ g r o u p ~ t o ~ C O N ~ g r o u p, ~}$ $n=4$ subpools/group

regulated genes were mainly involved in process of immune response, signaling transduction, pathways in cancer and metabolism, suggesting the inhibitory effects of maternal high fat intake on certain biological events. The maternal diet fat composition could change the maternal-to-fetal fatty acid transfer and intestinal membrane n- 6 and n-3 fatty acids composition of newborns, thus altering intestinal function [13]. In this study, therefore, it is rational that the addition of soy oil in maternal diet would induce alterations in intestinal physiology of fetus. Obviously, antigen processing and presentation in intestine could be inhibited by feeding HF diet, as indicated by the markedly decreasing gene expressions (i.e. SLA-1, SLA -DRB1, SLA-DQA1, CD74 and CD8, 1.5 2.5 fold reduction). Particularly, SLA-1, SLA -DRB1 and SLA-DQA1 are belonged to the highly polymorphic swine leucocyte antigen genes, which determine the immune response to disease and vaccine [17]. Among them, SLA-1 could interact with natural killer cells to prevent cytotoxicity [18], while SLA-DRB1 and -DQA1 mainly present exogenous peptides for $\mathrm{T}$ cells $[18,19]$. Previous studies have shown that maternal high fat 


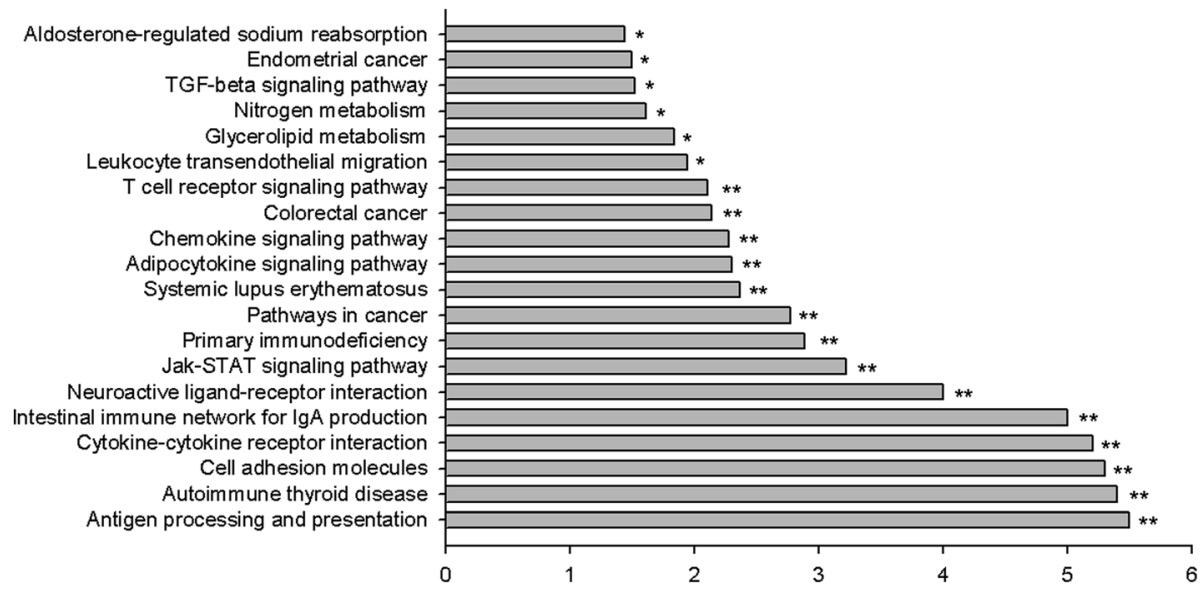

Fig. 4 Signal pathway enrichment analysis of fetal intestine by HF diet relative to CON diet ( $n=4$ subpools/group). The pathway terms were according to the down-regulated genes for certain biological processes, enriched categories are those identified as significantly enriched after multiple testing. ${ }^{*} P<0.05,{ }^{* *} P<0.01$. The value by horizontal axis resulted from negative value of Log (enrichment test $P$ value, base 10)

intake impaired intestinal barrier and immune system through altering immune cell homeostasis, such as the number of $\mathrm{T}$ cells and macrophages [13]. Furthermore, intestinal immune network for IgA production may be impaired by HF diet, as shown by the decreasing gene expression of CD40, IL-6 and TGF- 3 . These genes are required for $B$ cells proliferation and differentiation in Peyer's patches, their down-regulation would reduce the homing of $\mathrm{T}$ cells and $\mathrm{IgA}^{+}$plasma cells to the intestine, thus impair the immune homeostasis of intestine $[20,21]$.

Several signal transduction pathways related to inflammatory and immune response were affected by maternal high fat intake. For example, the TGF- $\beta$ signaling pathway was affected by HF diet, as indicated by the decreasing gene expression of TGF- $\beta$ and Bmp7 (approximately 1.6 fold reduction). TGF- $\beta$ is a multifunctional factor regulating cell growth, adhesion and differentiation $[22,23]$, also exerting anti-inflammatory effects by inhibiting NF- $\mathrm{kB}$ expression in the intestinal epithelium [24]. The oral administration of TGF- $\beta$ has been shown to decrease severity and incidence of necrotizing enterocolitis in neonatal rat necrotizing enterocolitis model [24]. In addition, feeding HF diet affected intestinal Jak-STAT signaling pathway, as shown by the decreasing gene expression of IL6, STAT2 and PIK3R5. The Jak-STAT signaling pathway is required for $\mathrm{T}$ cell differentiation, $\mathrm{B}$ cell maturation and secretion of SIgA [25], these down-regulated genes by HF diet may induce the abnormal intestinal innate immune response. Similarly, previous study demonstrated that maternal high protein diet would decrease liver mass, associated with altering gene expressions mapping to Jak-STAT signaling pathway in mouse offspring [26].

Furthermore, the lower expressions of TGF- $\beta$ and PIK3R5 genes by HF diet may affect the progression of colorectal cancer. TGF- $\beta 1 /$ Smads signaling pathway was demonstrated to mediate epithelial-to-mesenchymal transition, associated with the progression of colorectal cancer [27]. Mutation of PIK3R5 and other genes (i.e. PRKCZ, PTEN, RHEB and RPS6KB1) have altered PI3K signaling pathway, which is the central pathway for both colorectal and breast cancers [28]. Recent studies also indicated that maternal high fat diet would modify the susceptibility to breast cancer $[29,30]$, meanwhile it is dependent on fat or oil sources [31-33].

In this study, moreover, the markedly reduced glycerol kinase by feeding HF diet suggests the intestinal metabolism was altered. Glycerol kinase is required to release glycerol from glycerol-3-phosphate and dihydroxyacetone, and intestinal glycerol could produce $20 \sim 25 \%$ of total endogenous glucose under insulinopenia, suggesting the important role of glycerol in intestinal metabolism [34]. Although most of genes were markedly down-regulated by HF diet, some of genes (SOD2, CYP39A1, CCN2, SPARC et al.) were up-regulated. Particularly, SOD2, as an anti-oxidative enzyme in living cells, was highly expressed (1.75 fold change, $P=0.04$ ). Likewise, a recent study demonstrated that maternal high energy intake increased the expression of SOD in offspring ileum [5]. Previous study indicated that the increasing SOD gene is not necessarily associated with a better antioxidant capability, for example, the inflamed intestinal mucosa has been shown to contain higher SOD protein compared with normal tissues [35]. In addition, we found that feeding HF diet markedly increased gene expression of SULT1E by both DNA Microarray and RT-PCR analysis. SULT1E, as an estrogen-preferring drug metabolizing enzyme, its highly expression may be an compensatory response to high circulating estrogen, which occurs in dams fed high fat diet [36]. It has been shown 
Table 4 The markedly modified signal pathways in fetal intestine of gilts fed HF diet

\begin{tabular}{|c|c|c|c|c|}
\hline Name & Hits $^{a}$ & Total $^{\mathrm{b}}$ & Percent & $\begin{array}{l}\text { Enrichment test } \\
p \text { value }\end{array}$ \\
\hline Allograft rejection & 6 & 34 & $17.65 \%$ & 0.000 \\
\hline Antigen processing and presentation & 8 & 64 & $12.50 \%$ & 0.000 \\
\hline Autoimmune thyroid disease & 6 & 45 & $13.33 \%$ & 0.000 \\
\hline Cell adhesion molecules & 8 & 71 & $11.27 \%$ & 0.000 \\
\hline Cytokine-cytokine receptor interaction & 10 & 142 & $7.04 \%$ & 0.000 \\
\hline Hematopoietic cell lineage & 7 & 63 & $11.11 \%$ & 0.000 \\
\hline Intestinal immune network for IgA production & 7 & 48 & $14.58 \%$ & 0.000 \\
\hline Leishmania infection & 8 & 63 & $12.70 \%$ & 0.000 \\
\hline Viral myocarditis & 9 & 46 & $19.57 \%$ & 0.000 \\
\hline Graft-versus-host disease & 6 & 57 & $10.53 \%$ & $1 \mathrm{E}-04$ \\
\hline Neuroactive ligand-receptor interaction & 10 & 174 & $5.75 \%$ & $1 \mathrm{E}-04$ \\
\hline Type I diabetes mellitus & 5 & 40 & $12.50 \%$ & $2 \mathrm{E}-04$ \\
\hline Asthma & 5 & 50 & $10.00 \%$ & $5 \mathrm{E}-04$ \\
\hline Jak-STAT signaling pathway & 6 & 82 & $7.32 \%$ & $6 \mathrm{E}-04$ \\
\hline Primary immunodeficiency & 4 & 37 & $10.81 \%$ & 0.0013 \\
\hline Pathways in cancer & 7 & 140 & $5.00 \%$ & 0.0017 \\
\hline Hypertrophic cardiomyopathy & 4 & 43 & $9.30 \%$ & 0.0022 \\
\hline Systemic lupus erythematosus & 5 & 86 & $5.81 \%$ & 0.0043 \\
\hline Adipocytokine signaling pathway & 4 & 55 & $7.27 \%$ & 0.005 \\
\hline Chemokine signaling pathway & 5 & 90 & $5.56 \%$ & 0.0052 \\
\hline Colorectal cancer & 3 & 31 & $9.68 \%$ & 0.0072 \\
\hline Fc gamma R-mediated phagocytosis & 3 & 32 & $9.38 \%$ & 0.0078 \\
\hline T cell receptor signaling pathway & 4 & 63 & $6.35 \%$ & 0.0078 \\
\hline Leukocyte transendothelial migration & 4 & 71 & $5.63 \%$ & 0.0115 \\
\hline Acute myeloid leukemia & 3 & 39 & $7.69 \%$ & 0.0129 \\
\hline Dilated cardiomyopathy & 3 & 40 & $7.50 \%$ & 0.0137 \\
\hline Glycerolipid metabolism & 3 & 41 & $7.32 \%$ & 0.0146 \\
\hline Arrhythmogenic right ventricular cardiomyopathy & 3 & 47 & $6.38 \%$ & 0.0205 \\
\hline Nitrogen metabolism & 2 & 19 & $10.53 \%$ & 0.0246 \\
\hline TGF-beta signaling pathway & 3 & 55 & $5.45 \%$ & 0.0302 \\
\hline Endometrial cancer & 2 & 22 & $9.09 \%$ & 0.0316 \\
\hline Aldosterone-regulated sodium reabsorption & 2 & 24 & $8.33 \%$ & 0.0366 \\
\hline Type II diabetes mellitus & 2 & 24 & $8.33 \%$ & 0.0366 \\
\hline
\end{tabular}

${ }^{a}$ Hits mean the number of differential expressed genes within the particular GO term

bTotal: the total number of genes within the particular GO term

that the estrogen deletion by SULT1E over-expression is associated with the risk of developing different types of cancers $[28,37]$.

\section{Conclusion}

In summary, maternal high fat intake was able to increase fetal and intestinal weights as well as lactase activity, however, it altered the intestinal immune response, signal transduction and metabolism.

\section{Additional file}

Additional file 1: Effect of maternal high fat intake on gene expression of digestive enzymes in fetal intestine. (DOCX $34 \mathrm{~kb}$ )

\section{Competing interests}

The authors declare that they have no competing interests.

\section{Authors' contributions}

The authors' contributions are as follows: L-QC contributed to the study design and manuscript preparation; PLL, ZGY and LC carried out the study; LH, LLQ 
and RW contributed to the sample analysis; ZFF, YL, JL and SYX contributed to the data analysis; BF and DW contributed to the data interpretation. All authors read and approved the final manuscript.

\section{Acknowledgements}

We would like to thank the staff at our laboratory for their ongoing assistance.

\section{Funding}

The present study was supported by the National Natural Science Foundation of China (31101727) and the National Basic Research Program (973 Program) of China (No. 2013CB127306)

\section{Received: 21 February 2016 Accepted: 3 May 2016}

\section{Published online: 10 May 2016}

\section{References}

1. Wu G, Bazer FW, Wallace JM, Spencer TE. Board-invited review: intrauterine growth retardation: implications for the animal sciences. J Anim Sci. 2006;84: 2316-37.

2. Sangild PT. Gut responses to enteral nutrition in preterm infants and animals. Exp Biol Med (Maywood). 2006;231:1695-711.

3. Pinheiro DF, Pinheiro PF, Buratini Jr J, Castilho AC, Lima PF, Trinca LA, Vicentini-Paulino Mde L. Maternal protein restriction during pregnancy affects gene expression and immunolocalization of intestinal nutrient transporters in rats. Clin Sci (Lond). 2013;125:281-9.

4. Cao M, Che L, Wang J, Yang M, Su G, Fang Z, Lin Y, Xu S, Wu D. Effects of maternal over- and undernutrition on intestinal morphology, enzyme activity, and gene expression of nutrient transporters in newborn and weaned pigs. Nutrition. 2014;30:1442-7.

5. Xue Y, Wang H, Du M, Zhu MJ. Maternal obesity induces gut inflammation and impairs gut epithelial barrier function in nonobese diabetic mice. J Nutr Biochem. 2014;25:758-64.

6. Yan X, Huang Y, Wang H, Du M, Hess BW, Ford SP, Nathanielsz PW, Zhu MJ. Maternal obesity induces sustained inflammation in both fetal and offspring large intestine of sheep. Inflamm Bowel Dis. 2011:17:1513-22.

7. Gonzalez-Bulnes A, Astiz S, Ovilo C, Lopez-Bote CJ, Sanchez-Sanchez R, PerezSolana ML, Torres-Rovira L, Ayuso M, Gonzalez J. Early-postnatal changes in adiposity and lipids profile by transgenerational developmental programming in swine with obesity/leptin resistance. J Endocrinol. 2014;223:M17-29.

8. Zhang Q, Widmer G, Tzipori S. A pig model of the human gastrointestinal tract. Gut Microbes. 2013;4:193-200.

9. Heinritz SN, Mosenthin R, Weiss E. Use of pigs as a potential model for research into dietary modulation of the human gut microbiota. Nutr Res Rev. 2013:26:191-209.

10. Han F, Hu L, Xuan Y, Ding X, Luo Y, Bai S, He S, Zhang K, Che L. Effects of high nutrient intake on the growth performance, intestinal morphology and immune function of neonatal intra-uterine growth-retarded pigs. Br J Nutr. 2013;110:1819-27.

11. Hu L, Liu Y, Yan C, Peng X, Xu Q, Xuan Y, Han F, Tian G, Fang Z, Lin Y, et al. Postnatal nutritional restriction affects growth and immune function of piglets with intra-uterine growth restriction. Br J Nutr. 2015;114:53-62.

12. Che L, Chen H, Yu B, He J, Zheng P, Mao X, Yu J, Huang Z, Chen D. Longterm intake of pea fiber affects colonic barrier function, bacterial and transcriptional profile in pig model. Nutr Cancer. 2014;66:388-99.

13. Innis SM, Dai C, Wu X, Buchan AM, Jacobson K. Perinatal lipid nutrition alters early intestinal development and programs the response to experimental colitis in young adult rats. Am J Physiol Gastrointest Liver Physiol. 2010;299:G1376-1385.

14. Boudry G, Douard V, Mourot J, Lalles JP, Le Huerou-Luron I. Linseed oil in the maternal diet during gestation and lactation modifies fatty acid composition, mucosal architecture, and mast cell regulation of the ileal barrier in piglets. J Nutr. 2009;139:1110-7.

15. Desaldeleer C, Ferret-Bernard S, de Quelen F, Le Normand L, Perrier C, Savary G, Rome V, Michel C, Mourot J, Le Huerou-Luron I, Boudry G. Maternal 18:3n-3 favors piglet intestinal passage of LPS and promotes intestinal antiinflammatory response to this bacterial ligand. J Nutr Biochem. 2014;25:1090-8.

16. Heyman MB, Committee on N. Lactose intolerance in infants, children, and adolescents. Pediatrics. 2006:118:1279-86.

17. Ho CS, Lunney JK, Lee JH, Franzo-Romain MH, Martens GW, Rowland RR, Smith DM. Molecular characterization of swine leucocyte antigen class II genes in outbred pig populations. Anim Genet. 2010;41:428-32.
18. Lunney JK, Ho CS, Wysocki M, Smith DM. Molecular genetics of the swine major histocompatibility complex, the SLA complex. Dev Comp Immunol. 2009;33:362-74

19. Summerfield A, Guzylack-Piriou L, Schaub A, Carrasco CP, Tache V, Charley B, McCullough KC. Porcine peripheral blood dendritic cells and natural interferon-producing cells. Immunology. 2003;110:440-9.

20. Wang D, Dubois RN, Richmond A. The role of chemokines in intestinal inflammation and cancer. Curr Opin Pharmacol. 2009;9:688-96.

21. Chu VT, Beller A, Rausch S, Strandmark J, Zanker M, Arbach O, Kruglov A Berek $C$. Eosinophils promote generation and maintenance of immunoglobulin-A-expressing plasma cells and contribute to gut immune homeostasis. Immunity. 2014;40:582-93.

22. Massagué J. TGFß in cancer. Cell. 2008;134:215-30.

23. Van't Land B, Meijer H, Frerichs J, Koetsier M, Jager D, Smeets R, M'Rabet L, Hoijer M. Transforming Growth Factor- $\beta 2$ protects the small intestine during methotrexate treatment in rats possibly by reducing stem cell cycling. $\mathrm{Br}$ J Cancer. 2002:87:113-8.

24. Shiou SR, Yu Y, Guo Y, Westerhoff M, Lu L, Petrof EO, Sun J, Claud EC. Oral administration of transforming growth factor-beta1 (TGF-beta1) protects the immature gut from injury via Smad protein-dependent suppression of epithelial nuclear factor kappaB (NF-kappaB) signaling and proinflammatory cytokine production. J Biol Chem. 2013;288:34757-66.

25. Heneghan AF, Pierre JF, Kudsk KA. JAK-STAT and intestinal mucosal immunology. JAKSTAT. 2013;2:e25530.

26. Vanselow J, Kucia M, Langhammer M, Koczan D, Rehfeldt C, Metges CC. Hepatic expression of the GH/JAK/STAT/IGF pathway, acute-phase response signalling and complement system are affected in mouse offspring by prenatal and early postnatal exposure to maternal high-protein diet. Eur J Nutr. 2011:50:611-23.

27. Ji Q, Liu X, Han Z, Zhou L, Sui H, Yan L, Jiang H, Ren J, Cai J, Li Q. Resveratrol suppresses epithelial-to-mesenchymal transition in colorectal cancer through TGF- $\beta 1 /$ Smads signaling pathway mediated Snail/E-cadherin expression. BMC Cancer. 2015;15:1.

28. Wood LD, Parsons DW, Jones S, Lin J, Sjöblom T, Leary RJ, Shen D, Boca SM, Barber T, Ptak J. The genomic landscapes of human breast and colorectal cancers. Science. 2007;318:1108-13.

29. Montales MT, Melnyk SB, Simmen FA, Simmen RC. Maternal metabolic perturbations elicited by high-fat diet promote Wnt-1-induced mammary tumor risk in adult female offspring via long-term effects on mammary and systemic phenotypes. Carcinogenesis. 2014;35:2102-12.

30. de Oliveira AF, Fontelles CC, Rosim MP, de Oliveira TF, de Melo Loureiro AP, Mancini-Filho J, Rogero MM, Moreno FS, de Assis S, Barbisan LF, et al. Exposure to lard-based high-fat diet during fetal and lactation periods modifies breast cancer susceptibility in adulthood in rats. J Nutr Biochem. 2014;25:613-22.

31. Mabasa L, Cho K, Walters MW, Bae S, Park CS. Maternal dietary canola oil suppresses growth of mammary carcinogenesis in female rat offspring. Nutr Cancer. 2013:65:695-701.

32. Czuba AK, Mazurkiewicz M, Stanimirova-Daszykowska I. Enrichment of maternal diet with conjugated linoleic acids influences desaturases activity and fatty acids profile in livers and hepatic microsomes of the offspring with 7, 12-dimethylbenz [a] anthracene-induced mammary tumors. Acta Pol Pharm. 2014;71:747.

33. Su H-M, Hsieh P-H, Chen H-F. A maternal high n-6 fat diet with fish oil supplementation during pregnancy and lactation in rats decreases breast cancer risk in the female offspring. J Nutr Biochem. 2010;21:1033-7.

34. Croset M, Rajas F, Zitoun C, Hurot J-M, Montano S, Mithieux G. Rat small intestine is an insulin-sensitive gluconeogenic organ. Diabetes. 2001;50:740-6.

35. Kruidenier L, Kuiper I, van Duijn W, Marklund SL, van Hogezand RA, Lamers CB, Verspaget HW. Differential mucosal expression of three superoxide dismutase isoforms in inflammatory bowel disease. J Pathol. 2003;201:7-16.

36. Hilakivi-Clarke L, Clarke R, Onojafe I, Raygada M, Cho E, Lippman M. A maternal diet high in $n-6$ polyunsaturated fats alters mammary gland development, puberty onset, and breast cancer risk among female rat offspring. Proc Natl Acad Sci. 1997;94:9372-7.

37. Sharda DR, Miller-Lee JL, Kanski GM, Hunter JC, Lang CH, Kennett MJ, Korzick DH. Comparison of the agar block and Lieber-DeCarli diets to study chronic alcohol consumption in an aging model of Fischer 344 female rats. J Pharmacol Toxicol Methods. 2012;66:257-63. 